\title{
ANATOMIA DA MADEIRA DE AZARA URUGUAYENSIS (SPEG.) SLEUM. ${ }^{1}$ LUCIANO DENARDI ${ }^{2}$ JOSÉ NEWTON CARDOSO MARCHIORI $^{3}$ MARCOS ROBERTO FERREIRA ${ }^{4}$
}

\section{RESUMO}

É descrita e ilustrada com fotomicrografias a estrutura anatômica da madeira de Azara uruguayensis (Speg.) Sleum. Entre seus principais caracteres incluem-se placas de perfuração simples e escalariformes, traqueídeos vasculares e células perfuradas de raio.

Palavras-chave: Anatomia da madeira, Flacourtiaceae, Azara uruguayensis.

\section{ABSTRACT}

The wood anatomy of Azara uruguayensis (Speg.) Sleum. is described and illustrated with photomicrographs. Simple and scalariform perforation plates, vascular tracheids and perforated ray cells are the most important wood features.

Key words: Wood anatomy, Flacourtiaceae, Azara uruguayensis.

\section{INTRODUÇÃO}

A família Flacourtiaceae, de distribuição pantropical, reúne mais de 80 gêneros e 1.300 espécies, em sua maioria arbustivas ou árvores de porte pequeno a médio (Marchiori, 1997).

Com cerca de 20 espécies, o gênero Azara Ruiz \& Pavon distribui-se pelos Andes austrais e ilha de Juan Fernandez (Record \& Hess, 1949). Azara uruguayensis, um dos elementos andinos mais característicos da flora sul-rio-grandense, foge a esse padrão geográfico, ocorrendo na parte leste do planalto sul-brasileiro, desde as Serras do Itatiaia e Caparaó (Minas Gerais), até o Uruguai (Marchiori, 1997).

Com relação à anatomia da madeira, Record \& Hess (1949) e Metcalfe \& Chalk (1972) referem, para as Flacurtiáceas: anéis de crescimento ausentes ou pouco distintos; poros pequenos a muito pequenos, solitários ou em pequenos múltiplos; parênquima axial ausente ou muito escasso; e raios muito numerosos, heterogêneos, providos de células perfuradas, com raras células envolventes. As fibras, septadas, apresentam pontoações pequenas e indistintamente areoladas, ou então grandes e com aréolas distintas.

Para o gênero Azara, Miller (1975) refere: poros com 37-58-96 um de diâmetro, solitários ou em múltiplos radiais de 2-3, excepcionalmente até 16 poros; elementos vasculares com 404-526-704 $\mu \mathrm{m}$ de comprimento, com placas de perfuração simples, ocasionalmente escalariformes com mais de 4 barras; pontoações intervasculares alternas, menos comumente opostas, circulares até ovais e de 8-12 $\mu \mathrm{m}$ de diâmetro; fibrotraqueídeos com 687-901-1029 $\mu \mathrm{m}$ de comprimento, septados, de paredes finas; e cristais prismáticos freqüentes até ocasionais, nas células de raio. A esses aspectos, Record \& Hess (1949) agregam: pontoações raiovasculares escalariformes; placas de perfuração simples e escalariformes na mesma madeira;

1 Artigo recebido em 27/09/2005 e aceito para publicação em 24/10/2005.

2 Engenheiro Florestal, bolsista do CNPq, Doutorando do Programa de Pós-Graduação em Engenharia Florestal, Universidade Federal de Santa Maria, CEP 97105-900, Santa Maria (RS). lucianodenardi@yahoo.com.br

3 Engenheiro Florestal, Dr., Professor Titular do Departamento de Ciências Florestais, Centro de Ciências Rurais, Universidade Federal de Santa Maria, CEP 97105-900, Santa Maria (RS). balduinia@mail.ufsm.br

4 Acadêmico do Curso de Graduação em Engenharia Florestal, Universidade Federal de Santa Maria, CEP 97105-900, Santa Maria (RS). markus@mail.ufsm.br 
espessamentos espiralados em vasos; raios unisseriados com mais 20 células de altura; e raios multisseriados com 3-5 células de largura, 20-30 células de altura e longas margens unisseriadas. Para Azara petiolaris, Wagemann (1948) refere a presença de elementos vasculares com 350-650 $\mu \mathrm{m}$ de comprimento, com placas de perfuração simples e pontoações circulares de $9 \mu \mathrm{m}$ de diâmetro.

\section{MATERIAL E MÉTODOS}

O material em estudo consiste de uma amostra de madeira e respectivo material botânico, coletados em Canguçu - RS e anexados à Xiloteca e Herbário do Departamento de Ciências Florestais da Universidade Federal de Santa Maria (HDCF), sob o número 3222.

$\mathrm{Da}$ amostra de madeira, foram confeccionados três corpos-de-prova com $2 \mathrm{~cm}$ de lado, extraídos da porção mais externa do lenho e orientados para obtenção de cortes histológicos nos planos transversal, longitudinal radial e longitudinal tangencial. Um quarto bloco foi também retirado, com vistas à maceração.

No preparo das lâminas histológicas, seguiuse a técnica padrão no Laboratório de Anatomia da Madeira da Universidade Federal do Paraná: os corpos-de-prova foram amolecidos por fervura em água e seccionados em micrótomo de deslize, regulado na espessura de $18 \mu \mathrm{m}$. Os cortes foram tingidos com acridina-vermelha, crisodina e azul-de-astra (Dujardin,1964), desidratados em série alcoólica, diafanizados em xilol e montados em lâminas permanentes, com "Entellan".

No preparo de lâminas de macerado, o lenho foi dissociado pelo método de Jeffrey (Burger \& Richter,1991), usando-se coloração com safranina $1 \%$ e Entellan como meio de montagem.

A descrição microscópica baseia-se nas recomendações do IAWA Committee (1989) e a determinação dos diferentes tipos celulares, na metodologia proposta por Marchiori (1980); foram mensuradas, ainda, a altura e largura de raios, tanto em micrômetros como em número de células. Os dados quantitativos são apresentados na Tabela 1.

As fotomicrografias foram tomadas em aparelho Carl Zeiss, no Laboratório de Anatomia da Madeira da Universidade Federal do Paraná.

\section{DESCRIÇÃO MICROSCÓPICA}

Anéis de crescimento: Distintos, marcados por estreita camada de fibras achatadas radialmente, no lenho tardio.

Vasos: Dispostos em múltiplos radiais (Figura 1A, B), compondo cerca de $18 \%$ da seção transversal. Vasos em distribuição difusa (Figura 1A, B), poligonais (Figura 1B, C) e com $30 \pm 5$ (21-28) $\mu \mathrm{m}$ de diâmetro. Elementos vasculares de $570 \pm 119(380-730) \mu \mathrm{m}$ de comprimento, com apêndices em ambas as extremidades e placas de perfuração simples, ou então escalariformes, com 2-5 barras (Figura 2C), em posição vertical. Pontoações intervasculares alternas, geralmente arredondadas $(7,2 \pm 1,3(5,5-10,5) \mu \mathrm{m})$ e com abertura lenticular inclusa; pontoações raiovasculares horizontais até elípticas, de borda reduzida (Figura 2B). Espessamentos espiralados, tiloses e gomas, ausentes. Traqueídeos vasculares geralmente associados aos vasos e de comprimento semelhante aos elementos vasculares; apresentam pontoações tipicamente areoladas e aberturas cruzadas em "x", no par.

Parênquima axial: Ausente.

Raios: Com frequiência de $23 / \mathrm{mm}$, ocupando cerca de $20 \%$ da seção transversal. Raios de 13 células de largura (Figura 1D), menos comumente 4 células, com células procumbentes e margens de 4 ou mais fileiras de células quadradas e/ou eretas (Figura 2A). Raios unisseriados de $337 \pm 169(52-790) \mu \mathrm{m} \mathrm{e} 7 \pm 4$ (1-16) células de altura; raios multisseriados de $510 \pm 205(212-1095) \mu \mathrm{m}$ e $17 \pm 5(8-29)$ células de altura (Figura 1D). Células envolventes e cristais prismáticos, ocasionais, 

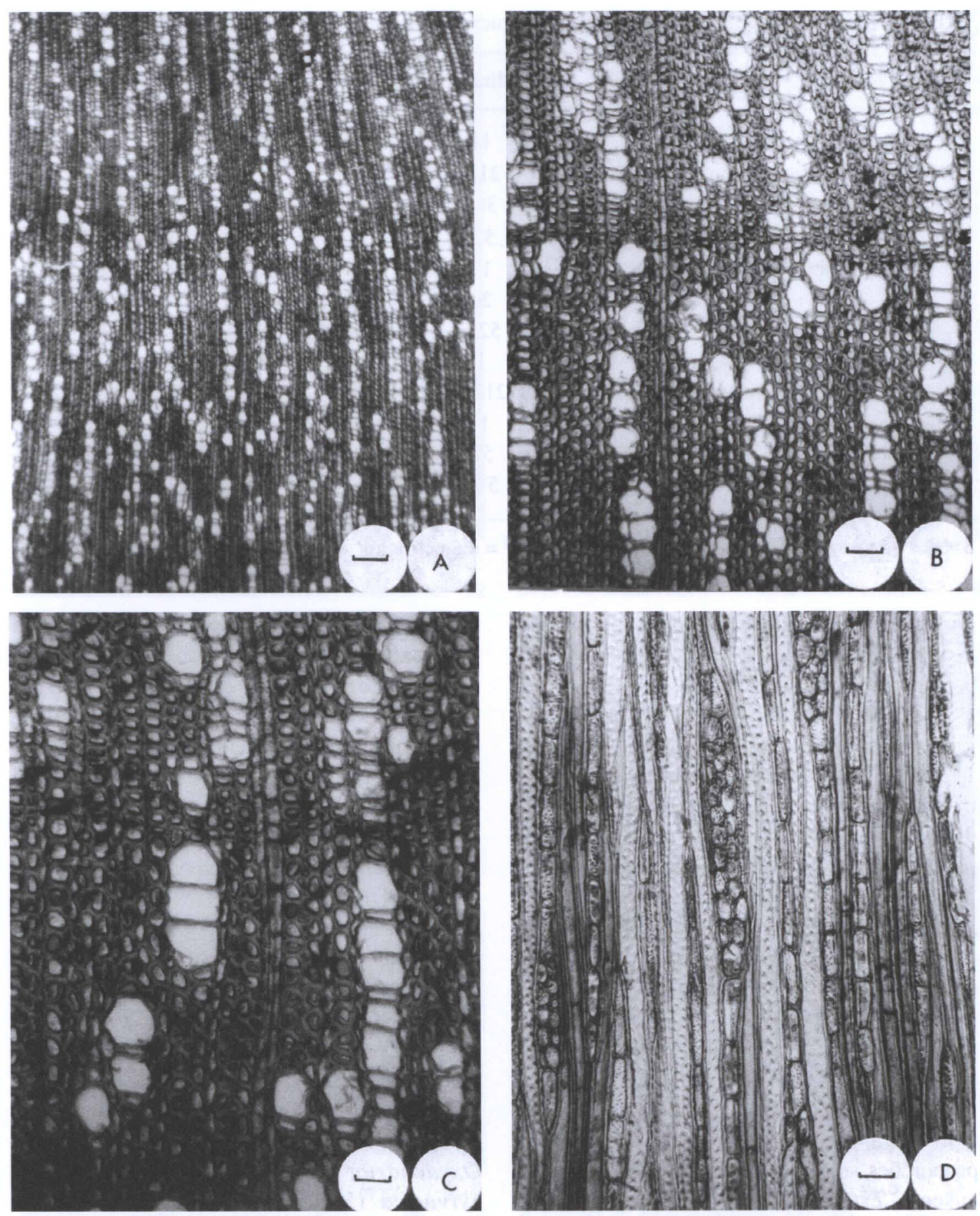

FIGURA 1 - Seção transversal da madeira, mostrando porosidade difusa e poros em múltiplos radiais (A). Poros de seção poligonal em múltiplos radiais, e limite de anel de crescimento marcado por fibras radialmente estreitas, em plano transversal (B). Mesmos aspectos, com maior aumento (C). Raios com 1 - 3 células de largura e longas margens unisseriadas, em seção longitudinal tangencial (D). Escalas = $100 \mu \mathrm{m}$ (A); $40 \mu \mathrm{m}$ (B); $25 \mu \mathrm{m}(\mathrm{C}, \mathrm{D})$. 
TABELA 1: Dados quantitativos da estrutura anatômica.

\begin{tabular}{lccccc}
\hline Característica & Mínimo & Média & Máximo & S & CV $(\%)$ \\
\hline Fração de vasos $(\%)$ & 11 & 18,4 & 21 & 4,33 & 23,6 \\
$\varnothing$ do lume de vasos $(\mu \mathrm{m})$ & 21,2 & 30,8 & 38,8 & 5,29 & 17,2 \\
Comprimento de elementos vasculares $(\mu \mathrm{m})$ & 380 & 570 & 730 & 119,30 & 20,9 \\
$\varnothing$ de pontoações intervasculares $(\mu \mathrm{m})$ & 5,5 & 7,2 & 10,5 & 1,35 & 18,7 \\
Fração de raios $(\%)$ & 15 & 20 & 22 & 2,83 & 14,1 \\
Freqüência de raios $(\mathrm{mm})$ & 20 & 23 & 27 & 2,00 & 8,7 \\
Altura de raios unisseriados $(\mu \mathrm{m})$ & 52,5 & 337,1 & 790 & 168,94 & 50,1 \\
Altura de raios unisseriados $($ células) & 1 & 7 & 16 & 3,75 & 53,6 \\
Altura de raios multisseriados $(\mu \mathrm{m})$ & 212,5 & 510,3 & 1095 & 205,84 & 40,3 \\
Altura de raios multisseriados $($ células) & 8 & 17 & 29 & 5,10 & 30 \\
Fração de fibras $(\%)$ & 58 & 61,6 & 68 & 4,33 & 7 \\
Comprimento de fibras $(\mu \mathrm{m})$ & 580 & 873,6 & 1120 & 153,13 & 17,5 \\
\hline
\end{tabular}

$\mathrm{S}=$ desvio padrão; $\mathrm{CV}=$ coeficiente de variação; $\varnothing=$ diâmetro; $\mu \mathrm{m}=$ micrômetros .

na margem de raios. Células perfuradas, visivelmente maiores do que as adjacentes, com perfurações simples ou escalariformes.

Fibras: Tecido fibroso proeminente (62\%). Fibras septadas (Figura 2D) de $870 \pm 153(580$ 1120) $\mu \mathrm{m}$ de comprimento, com paredes estreitas a espessas e pontoações areoladas diminutas (inferiores a $3 \mu \mathrm{m}$ ), na face radial da parede. Espessamentos espiralados, ausentes.

\section{ANÁLISE DA ESTRUTURA ANATÔMICA}

A madeira de Azara uruguayensis concorda, em linhas gerais, com o descrito por Record \& Hess (1949) e Metcalfe \& Chalk (1972) para as Flacourtiaceae e, por Miller (1975), para o gênero Azara.

O lenho, composto predominantemente de fibras (62\%), apresenta raios e vasos em proporções semelhantes. O parênquima axial, ausente, está de acordo com o referido na literatura.

Os valores de diâmetro de poros e de altura de raios unisseriados (em número de células) divergem do referido por Miller (1975), para Azara. Ao contrário do descrito por Record \&
Hess (1949), não foram observados espessamentos espiralados no material em estudo. Com relação ao comprimento de elementos vasculares, ao diâmetro de pontoações intervaculares, à altura de raios multisseriados (em número de células) e ao comprimento de fibras, os valores observados aproximam-se dos referidos na literatura.

A presença de placas de perfuração simples e escalariformes em Azara uruguayensis concorda com o referido por Record \& Hess (1949) para o gênero, mas difere do observado por Wagemann (1948) para Azara petiolaris, que apresenta apenas de placas de perfuração simples. A ocorrência de mais de um tipo de placa de perfuração na mesma madeira, caráter pouco comum, foi também observado em Didymopanax morototonii (Araliaceae), Oxydendrun arboreum (Ericaceae), Fagus sylvatica (Fagaceae) e em espécies de Platanaceae (IAWA Committe, 1989).

A presença de traqueídeos vasculares constitui novidade para as Flacourtiaceae. De difícil identificação em plano transversal, eles são facilmente reconhecidos nos planos 

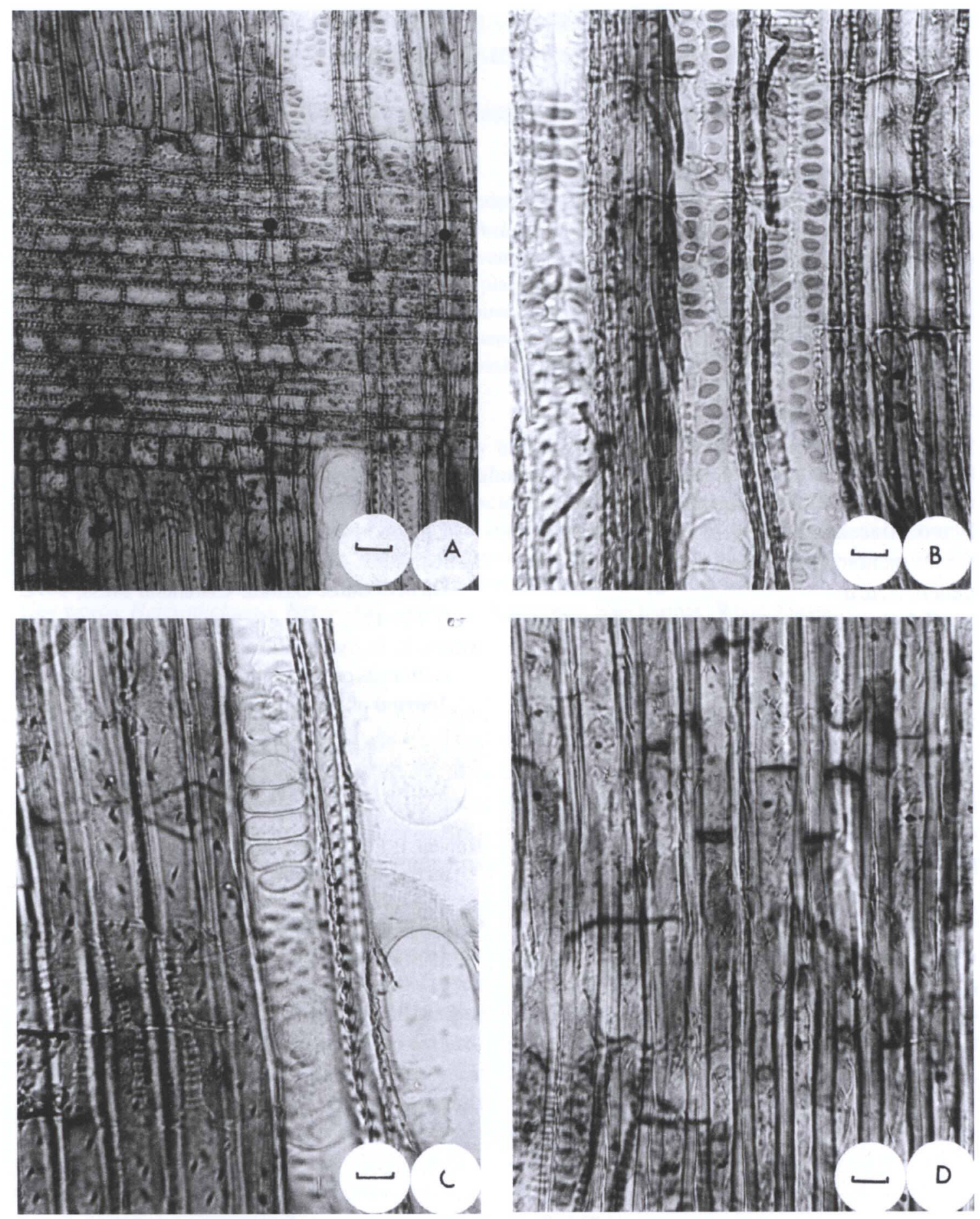

FIGURA 2 - Raio heterogêneo e placa de perfuração simples, em plano longitudinal radial (A). Pontoações raio-vasculares horizontais até elípticas, em seção longitudinal radial (B). Fibras com pontoações areoladas diminutas e placas de perfuração simples e escalariforme, em seção longitudinal radial (C). Fibras septadas, em seção longitudinal tangencial (D). Escalas $=25 \mu \mathrm{m}(\mathrm{A}) ; 12,5 \mu \mathrm{m}$ (B, C, D). 
tangencial e radial, distinguindo-se das fibras por seu menor comprimento, bem como pela presença de pontoações areoladas conspícuas. A distinção entre traqueídeos vasculares e elementos vasculares é dificultada pela semelhança dos mesmos quanto ao comprimento, forma e natureza das pontoações; a ausência de perfurações, todavia, bem como as pontoações com aberturas cruzadas em " $x$ ", no par, comprovam a presença de traqueídeos vasculares no material em estudo.

As células perfuradas de raio, embora escassas, são maiores que as células adjacentes, fato também constatado por Chalk \& Chattaway (1933), Rundall (1985) e Ceccantini \& Angyalossy-Alfonso (2000), para outras espécies. Tais células, tidas como freqüentes em Flacourtiaceae (Record \& Hess, 1949), não foram mencionadas, por Miller (1975), para o gênero Azara.

Cabe comentar, ainda, que a alternância de faixas tangenciais de fibras com paredes finas e espessas (parenchyma-like), confere ao plano transversal a falsa impressão de parênquima axial, aspecto ausente na madeira em estudo.

\section{REFERÊNCIAS BIBLIOGRÁFICAS}

Burger, L. M., Richter, H. G. Anatomia da Madeira. São Paulo: Ed. Nobel, 1991. 154p.

Ceccantini, G. C. T., Angyalossy-Alfonso, V.
Perforeted ray cells in Bathysa meridionalis (Rubiaceae). IAWA Bull., v. 21, n. 1, p. 77-82, 2000.

Chalk, L., Chattaway, M. M. Perfored ray cells. Proc. Royal Soc. Lond, n. 133, p. 82-92, 1933.

Dujardin, E. P. Eine neue Holz-Zellulosenfaerbung. Mikrokosmos, n. 53, p. 94, 1964.

IAWA Committee. IAWA list of microscopic features for hardwood identification. IAWA Bull., v.10, n. 3, p. 218-359, 1989.

Marchiori, J. N. C. Estudo anatômico do xilema secundário de algumas espécies dos gêneros Acacia e Mimosa, nativas no Estado do Rio Grande do Sul. 1980. 186f. Dissertação (Mestrado em Engenharia Florestal) Universidade Federal do Paraná, Curitiba.

Marchiori, J. N. C. Dendrologia das angiospermas: Das Magnoliáceas às Flacurtiáceas. Santa Maria: UFSM, 1997. p. 223-245.

Metcalfe, C. R., Chalk, L. Anatomy of the Dicotyledons. Oxford: Clarendon Press, 1972. p. 121-123.

Miller, R. B. Systematic anatomy of the xylem and comments on the relationships of Flacourtiaceae. Journal of the Arnold Arboretum, v. 56, n. 1, p. 20-64. 1975.

Record, S. J., Hess, R. W. Timbers of the New World. New Haven: Yale University Press, 1949. p. 170-175.

Rundal, P. Perfored ray cells in Hyptis hagei - a new record for Labiatae. IAWA Bull., n. 6, p. 161$162,1985$.

Wagemann, G. Maderas chilenas. Lilloa, n. 16, p. 332-333, 1948. 